\title{
18. ORGANIC GEOCHEMICAL STUDIES: INTRODUCTION AND SUMMARY
}

\author{
John M. Hunt, Woods Hole Oceanographic Institution, Woods Hole, Massachusetts
}

The organic geochemical studies were aimed at following diagenetic changes in organic matter with depth, particularly in the reducing environment of the Cariaco Trench. Core samples were analyzed for hydrocarbons, fatty acids, fatty alcohols, steroidal compounds, chlorophyll derivatives, amino acids, amino sugars, and ammonia at selected depths at Site 147 in the Cariaco Trench. In addition, the racemization of isoleucine was followed in a carbonate section at Site 148 .

The percent organic carbon in the Cariaco Trench samples was about 4 percent in the first thirteen meters, 0.6 percent at 62 meters, and in the range 1.3 to 2.7 percent at all other depths analyzed. These data indicate that reducing conditions were strongest during the last 20,000 years of deposition, and that at least one strong oxidizing cycle occurred when the samples around 62 meters were deposited about 125,000 years ago. Samples in this range also show a somewhat higher contribution of terrestrial organic matter, as indicated by the isotopically lighter organic carbon, and the presence of land-derived compounds such as triterpenoids.

Samples from the first thirteen meters are characterized by a high content of bitumens rich in asphaltenes and by a low content of hydrocarbons. This is typical of young, relatively unaltered organic matter. The quantity and nature of hydrocarbons in the $C_{4}$ to $C_{7}$ and $C_{13}$ to higher $\mathrm{C}$ ranges indicate that there has been essentially no thermal alteration of the organic matter in the deepest sample analyzed at 127 meters.

Mass spectral analyses of the organic extracts showed that both phytadiene and norphytene derived from plankton are major constituents of the hydrocarbons at 6 meters, but show a considerable decrease in the deeper samples. The phytane and pristane which would form from them is present, but not in the deeper samples in sufficient quantity to account for the loss of phytadiene and norphytene. It is suggested that part of these olefins are incorporated in the kerogen matrix. There is also the possibility that more phytadiene and norphytene were preserved at 6 meters, due to stronger reducing conditions, than in the deeper samples at the time of deposition.

Sterols such as cholesterol, ergosterol and $\beta$-sitosterol appear to decrease with increasing depth. Both sterenes and steranes are present as reduction products of the sterols. Pentacyclic triterpanes such as lupane, which are derived from land-plant material, were found only in the deeper samples at 67 and 138 meters. Fatty acids and alcohols with carbon numbers above $\mathrm{C}_{20}$, which is characteristic of the waxes of higher terrestrial plants, were also found in a sample at 80 meters along with triterpane hydrocarbons.

Chlorophyll derivatives were analyzed in seven samples ranging from 5 to 107 meters in depth. All tetrapyrrole pigments were of the chlorin type. Metallo-chlorins and porphyrins were not present in recognizable amounts. The initial steps in the degradation of chlorophyll in the Cariaco Trench appeared to be demetallation followed by reduction of the double bond in phytol. Hydrolysis of the phytol group appears to occur simultaneously with the opening of the isocyclic ring. There was no evidence for reduction of the 2-vinyl group to the maximum depth of 107 meters. In general, diagenetic changes of chlorophyll derivatives in the Cariaco Trench appear to be slower than in lacustrine and nearshore sediments.

Amino acids released by $\mathrm{HC} 1$ hydrolysis were found to decrease by factors of up to ten in going from 1 meters to 110 meters in depth. Less than 10 percent of the aspartic acid at the surface was present at 110 meters. The amino sugars and nonprotein amino acids, some of which are diagenetic products, did not show this steady decrease. Ammonia increased with depth, indicating that it was forming from the deamination of some of the amino acids. Racemization of allo-isoleucine to isoleucine did not occur in the Cariaco Trench clays in the same manner as it does in the carbonate sediments. Little difference was observed in this ratio between the 1- and 80-meter levels.

Racemization of L-isoleucine to D-allo-isoleucine was followed in various organic fractions extracted from sediments extending from 2 to 232 meters in depth at Site 148 in the Caribbean sea. The carbonate content of the first ten meters of core exceeded 30 percent and contained enough foraminiferal tests to enable sediment ages to be estimated from the alleu/iso ratio. An average sedimentation rate of $5.9 \mathrm{~cm} / 10^{3} \mathrm{y}$ was estimated for the first ten meters of this core, based on the alleu/iso ratio. 